\title{
Tolerância à inundação de Cecropia pachystachya Trec. (Cecropiaceae): aspectos ecofisiológicos e morfoanatômicos
}

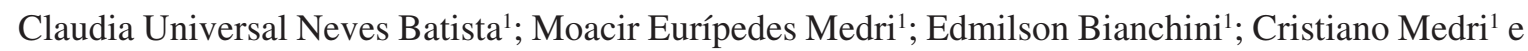 \\ José Antonio Pimenta ${ }^{1,2}$
}

Recebido em 15/01/2007. Aceito em 2/05/2007

\begin{abstract}
RESUMO - (Tolerância à inundação de Cecropia pachystachya Trec. (Cecropiaceae): aspectos ecofisiológicos e morfoanatômicos). Visando elucidar aspectos da tolerância à hipoxia, plantas de Cecropia pachystachya foram submetidas a 30 dias de inundação. $\mathrm{O}$ crescimento e desenvolvimento, a condutância estomática, a fotossíntese e a morfo-anatomia foram avaliadas. A taxa de crescimento relativo (TCR) da raiz e do caule foi inferior em plantas alagadas, não havendo diferenças nesta taxa para as folhas e para a planta inteira. A não variação na TCR das folhas pode ter sido em função da maior esclerofilia foliar das plantas alagadas, que apresentaram menor área. A condutância estomática e a taxa fotossintética diminuíram nas plantas submetidas ao alagamento. Foram observadas alterações morfoanatômicas em caules e principalmente em raízes de plantas alagadas. A análise dos resultados indica que a tolerância desta espécie a períodos de inundação está relacionada à sua capacidade de manter uma satisfatória produção energética. A manutenção de um balanço energético positivo possibilita que mesmo sob estresse, com queda na taxa fotossintética, as plantas desta espécie apresentem uma considerável TCR. Portanto, C. pachystachya pode ser forte competidora em áreas sujeitas ao alagamento.
\end{abstract}

Palavras-chave: alagamento, anatomia ecológica, Cecropia pachystachya, fotossíntese, TCR

\begin{abstract}
Flood tolerance in Cecropia pachystachya Trec. (Cecropiaceae): ecophysiological and morpho-anatomical aspects). To elucidate certain aspects of hypoxia tolerance in Cecropia pachystachya, plants were submitted to 30 days of flooding. Growth and development, stomatal conductance, photosynthetic rates and morpho-anatomy were studied. Root and stem relative growth rates (RGR) were lower in flooded plants. There was no difference in leaf RGR and whole plant RGR. The maintenance of leaf RGR is possibly related to greater sclerophylly in flooded plants. Stomatal conductance and photosynthetic rate decreased due to flooding. Stems and roots, especially the latter, showed morpho-anatomical alterations in flooded plants. The results so far suggest that flood tolerance in C. pachystachya is related to the capacity to maintain satisfactory energy production. The maintenance of a positive energy balance allows this species to maintain a substantial RGR, even under stress with a lower photosynthetic rate. Therefore $C$. pachystachya may be a strong competitor in flooded areas.
\end{abstract}

Key words: Cecropia pachystachya, ecological anatomy, flooding, photosynthesis, RGR

\section{Introdução}

Nas matas ciliares freqüentemente ocorrem áreas sujeitas à inundação com características abióticas próprias, tais como, fertilidade do solo, temperatura, oxigenação, etc. (Rodrigues 1989), que atuam como fatores de seleção para a vegetação, determinando sua distribuição (Mantovani et al. 1989). Isto ocorre porque o solo tornando-se hipóxico devido ao alagamento leva as raízes a uma situação de estresse, fazendo com que as plantas respondam com maior ou menor eficiência, permitindo distinção entre espécies tolerantes e intolerantes (Armstrong et al. 1994).

A hipoxia provoca variações na respiração aeróbia (Joly 1994; Rogge et al. 1998; Matsui \& Tsuchiya
2006) no nível nutricional (Drew 1991; Medri et al. 2002; Alaoui-Sossé et al. 2005) e na fotossíntese (Liao \& Lin 1996; Olivella et al. 2000; Pryor et al. 2006; Fernandez 2006) o que podem afetar o crescimento e desenvolvimento das diferentes partes da planta em um ambiente alagado (Medri et al. 1998; Medri et al. 2002; Davanso et al. 2002; Pryor et al. 2006). Além disso, as plantas apresentam modificações morfológicas e anatômicas quando submetidas ao alagamento (Armstrong et al. 1994; Evans 2004). Comumente ocorre a hipertrofia de lenticelas, formação de aerênquima, enraizamento adventício e formação de raízes diageotrópicas (Pimenta et al. 1996; Kolb et al. 1998; Mano et al. 2006), que podem facilitar tanto a difusão de oxigênio da parte aérea para as raízes, como

\footnotetext{
1 Universidade Estadual de Londrina, Departamento de Biologia Animal e Vegetal, Centro de Ciências Biológicas, C. Postal 6001, 86051-970 Londrina, PR, Brasil

2 Autor para correspondência: pimenta@uel.br
} 
a eliminação de produtos voláteis potencialmente tóxicos, como etanol, etileno e acetaldeído, que muitas vezes acumulam durante a hipoxia (Tsukahara \& Kozlowski 1985; Joly 1991). A capacidade de produzir estas modificações morfoanatômicas pode determinar o nível de tolerância de uma determinada espécie ao alagamento (Laan et al. 1991).

Cecropia pachystachya Trec. (Cecropiaceae), conhecida como imbaúba, é uma árvore de comportamento pioneiro, de rápido crescimento, seletiva higrófila, característica de solos úmidos, ocorrendo em matas ciliares, bordas de florestas e clareiras. Prefere florestas secundárias, raramente aparecendo no interior de florestas primárias densas (Lorenzi 1992). É uma espécie frequiente em áreas sujeitas a alagamentos periódicos (variando de aproximadamente cinco a no máximo 30 dias), no entanto pouco ou nada se sabe sobre as respostas ecofisiológicas e morfoanatômicas que esta espécie apresenta quando submetida à inundação. Com o objetivo de descrever quais seriam estas respostas, foram levantadas as seguintes questões: Há alterações no crescimento e desenvolvimento de indivíduos de C. pachystachya submetidos ao alagamento? A condutância estomática e a taxa fotossintética são afetadas pelo alagamento? Quais as possíveis alterações morfo-anatômicas de caules e de raízes desta espécie quando cultivadas em solo alagado?

\section{Material e métodos}

O estudo foi desenvolvido em casa de vegetação na Universidade Estadual de Londrina. Depois de retiradas dos frutos, sementes de cinco matrizes de C. pachystachya foram lavadas e secas por 10 dias à sombra e colocadas para germinar em recipientes contendo $700 \mathrm{~g}$ de substrato úmido constituído de $80 \%$ de terra e $20 \%$ de uma mistura de palha de grama, cama de frango, calcário e borra de café. Após cerca de dois meses, as plantas jovens foram levadas para casa de vegetação e, juntamente com o substrato, foram colocadas em vasos plásticos de quatro litros contendo solo peneirado e areia na proporção 3:1. Um mês após a aclimatação das plantas em casa de vegetação, em delineamento inteiramente casualizado, deu-se início ao experimento.

As avaliações ecofisiológicas e morfoanatômicas foram realizadas em plantas cultivadas nos vasos plásticos com solo drenado (D), que serviu como grupo controle e em plantas cultivadas nos vasos plásticos com solo alagado por até 30 dias (A), período máximo aproximado que a espécie pode ficar exposta a esta condição em condições naturais. Com reposições diárias, o nível da água foi mantido a dois centímetros acima do solo.

Para o estudo do crescimento e desenvolvimento vegetativo, no início do experimento e após 30 dias, dez plantas controles e dez submetidas ao alagamento foram separadas em raiz, caule e folha e colocadas para secar em estufa a $70{ }^{\circ} \mathrm{C}$ por 72 horas, tempo suficiente para atingir peso constante e, pesadas em balança semi-analítica. A partir disto calculou-se a taxa de crescimento relativo (TCR) para cada parte da planta e para a planta como um todo, utilizando-se a fórmula: TCR= lnMSf-lnMSi / tempo, onde MSf e MSi são, respectivamente, as massas secas finais e iniciais.

Foram determinados também a área foliar total e o diâmetro do caule das plantas alagadas por 30 dias e das não alagadas, utilizando-se planímetro e paquímetro, respectivamente. Com os dados de massa seca e área foliar total, calculou-se o índice de esclerofilia a partir da fórmula: MSff/AFf, onde MSff é a massa seca foliar final e AFf é a área foliar final. Além disso, ao final de 30 dias de alagamento foram feitas as contagens do número de lenticelas por $\mathrm{cm}^{2} \mathrm{e}$ do número de raízes adventícias que apareceram durante o período de alagamento.

A condutância estomática e a taxa fotossintética foram avaliadas com um analisador de gases por infravermelho portátil modelo LI-6200 (Li-Cor), utilizando-se sempre uma folha totalmente expandida do segundo nó a partir do ápice de cada planta, com aproximadamente 25 segundos de leitura em cada folha. Para a realização de tais medidas, foram utilizadas 24 plantas cultivadas nas seguintes condições: seis em solo drenado, seis em solo alagado por dois, seis em solo alagado por cinco e seis em solo alagado por 15 dias. Ocorridas todas no mesmo dia, as avaliações iniciaram-se às nove horas e foram realizadas em seis etapas, tomando-se a cada uma delas, medidas de folhas de cada um dos tratamentos.

Os estudos anatômicos foram realizados com plantas cultivadas em solo drenado e em solo alagado por 30 dias. Foram usadas dez plantas controles e dez submetidas ao alagamento, utilizando-se de raízes pivotantes e secundárias (sendo que para as plantas alagadas analisaram-se raízes secundárias diageotrópicas formadas durante o alagamento), e de caule.

Para estudos anatômicos, raízes foram seccionadas a $2 \mathrm{~cm}$ de seus ápices, retirando-se segmentos de $0,5 \mathrm{~cm}$. O caule foi seccionado na altura do colo, retirando-se segmentos de $1 \mathrm{~cm}$. 
Os segmentos foram fixados em F.A.A. 70, desidratados e diafanizados na série etanol-xilol e incluídos em parafina (Johansen 1940). Os blocos foram cortados e as secções, de $12 \mu \mathrm{m}$, foram coradas com azul de astra e fucsina básica (Luque et al. 1996) e montadas em bálsamo do Canadá.

As lâminas foram analisadas e fotografadas em microscópio de luz. Com a ajuda de uma ocular micrométrica, as seguintes variáveis foram medidas no córtex da raiz pivotante e das raízes secundárias: espessura do tecido, número de camadas de células e diâmetro das células. Para o caule, além das variáveis avaliadas para as raízes, avaliou-se também o diâmetro dos elementos de vaso. e o diâmetro do cilindro central.

Os dados foram submetidos à análise de variância (ANOVA) e as médias fora comparadas pelo teste de Tukey, considerando um nível de significância de 5\%.

\section{Resultados}

As TCR da raiz e do caule apresentaram uma discreta diminuição nas plantas submetidas a 30 dias de alagamento, no entanto, não houve diferença deste parâmetro para as folhas e para a planta inteira (Tab. 1).

Plantas submetidas ao alagamento por 30 dias apresentaram áreas foliares inferiores às cultivadas em solo drenado (Fig. 1A). Entretanto, as folhas das plantas que foram alagadas apresentaram um maior índice de esclerofilia do que as folhas daquelas plantas que desenvolveram por todo tempo em solo drenado (Fig. 1B).

O alagamento provocou redução na condutância estomática nos três períodos analisados, ou seja, dois, cinco e 15 dias (Fig. 2A). A taxa fotossintética também diminuiu nas plantas submetidas ao solo alagado, sendo que com 15 dias de alagamento a redução foi mais pronunciada do que a dois e cinco dias (Fig. 2B).

Tabela 1. Taxa de crescimento relativo (TCR) da raiz, caule, folhas e planta inteira de Cecropia pachystachya Trec., mantidas em solo drenado (D) e alagado por 30 dias (A). Médias seguidas de letras iguais nas colunas não diferem pelo teste de Tukey $(\leq 0,05$, $\mathrm{n}=10$ ).

\begin{tabular}{lcccc}
\hline \multirow{4}{*}{ Tratamento } & Raiz & $\begin{array}{c}\text { Caule } \\
\left(\mathrm{mg} \mathrm{g}^{-1} \mathrm{~d}^{-1}\right)\end{array}$ & Folha & Planta inteira \\
\cline { 2 - 5 } & \multicolumn{4}{c}{ TCR } \\
\hline $\mathrm{D}$ & $25,61 \mathrm{a}$ & $24,00 \mathrm{a}$ & $16,91 \mathrm{a}$ & $21,18 \mathrm{a}$ \\
$\mathrm{A}$ & $22,44 \mathrm{~b}$ & $19,60 \mathrm{~b}$ & $15,93 \mathrm{a}$ & $18,71 \mathrm{a}$ \\
\hline
\end{tabular}
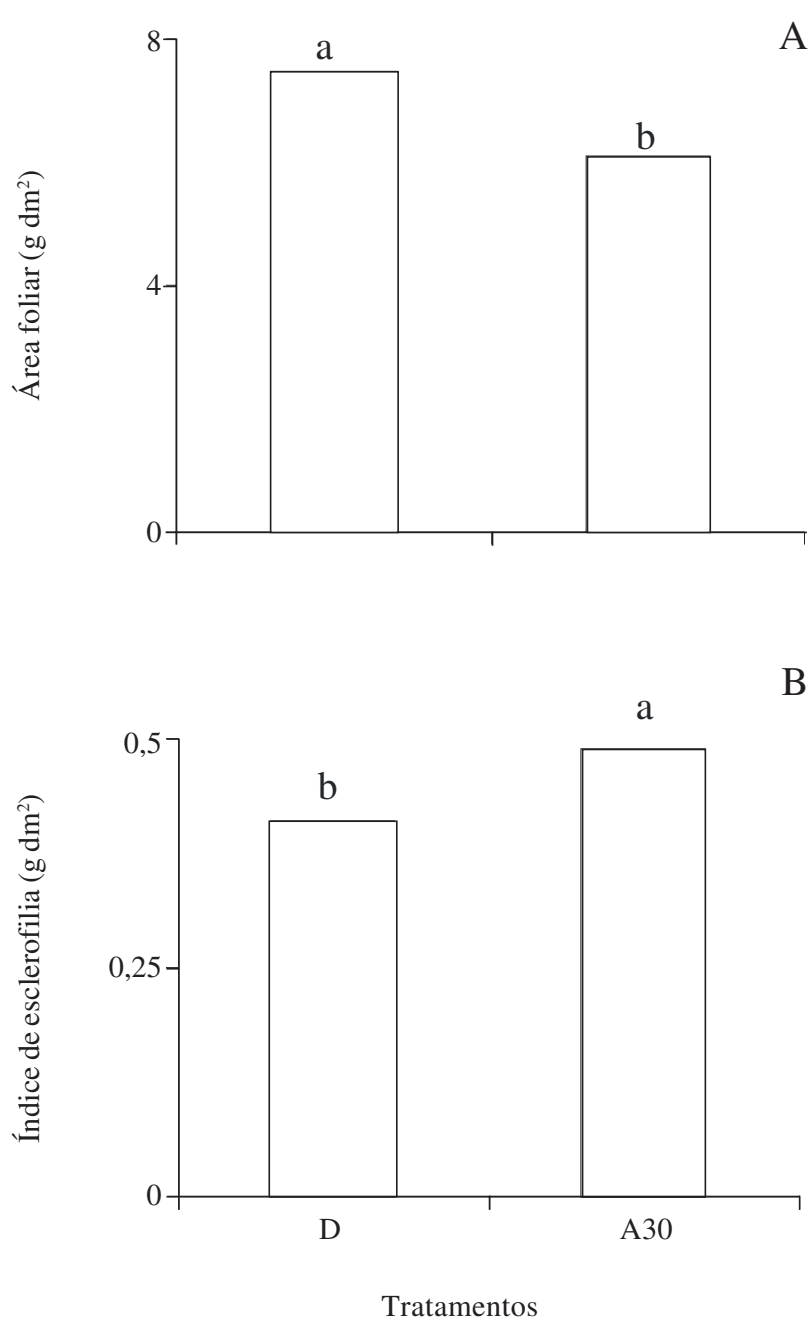

Figura 1. Área foliar (A) e índice de esclerofilia (B) de plantas de Cecropia pachystachya Trec. cultivadas em solo drenado (D) e alagado por 30 dias (A30). Diferentes letras acima das barras indicam diferenças pelo teste de Tukey $(\leq 0,05, \mathrm{n}=10)$.

Comparadas com as plantas mantidas em solo drenado, o alagamento por 30 dias não provocou efeito sobre o diâmetro da base do caule das plantas de C. pachystachya (Tab. 2). Ocorreu aumento do número de lenticelas e aparecimento de raízes adventícias nas plantas submetidas à inundação (Tab. 2).

Embora nas plantas submetidas ao alagamento por 30 dias, não tenha ocorrido variação no número de camadas de células, a espessura do córtex da raiz pivotante apresentou um grande aumento, assim como o diâmetro das suas células (Tab. 2). Nas raízes secundárias, tanto a espessura do córtex quanto o número de camadas de células deste tecido apresentaram um aumento nas plantas cultivadas em solo alagado por 30 dias. $\mathrm{O}$ mesmo ocorreu com o diâmetro das células do córtex (Tab. 2). 


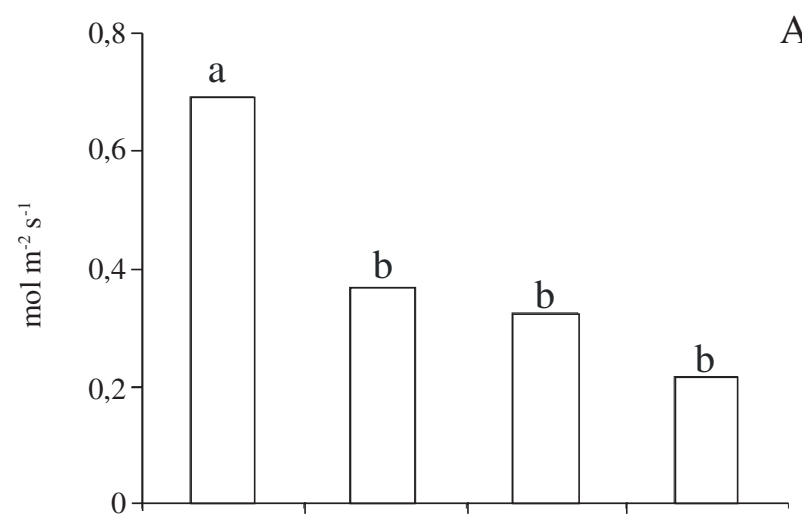

Analisando-se o caule, observou-se que a espessura, número de camadas de células e diâmetro das células do córtex não apresentaram diferenças nas plantas alagadas por 30 dias quando comparadas com aquelas de solo drenado (Tab. 2). No entanto, neste órgão o diâmetro dos elementos de vaso foram maiores nas plantas não alagadas (Tab. 2).

As lenticelas das plantas cultivadas em solo alagado por 30 dias apresentaram-se mais proeminentes e com poucas células suberizadas no tecido de enchimento, quando comparadas com as lenticelas das plantas mantidas em solo drenado (Fig. 3).

\section{B Discussão}

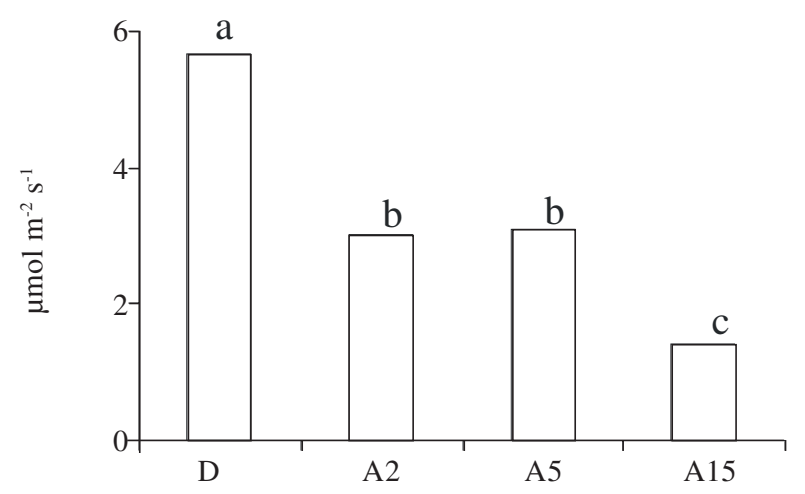

Figura 2. Condutância estomática (A) e taxa fotossintética (B) de plantas de Cecropia pachystachya Trec. cultivadas em solo drenado (D) e alagado por dois (A2), cinco (A5) e 15 (A15) dias. Barras seguidas de letras iguais não diferem pelo teste de Tukey $(\leq 0,05, \mathrm{n}=10)$.

As plantas de C. pachystachya apresentaram diminuição nas TCR da raiz e do caule, mas nas folhas e na planta como um todo não houve reduções. Isto pode ter ocorrido devido à não variação da massa seca das folhas devido ao aumento na esclerofilia foliar, apesar das plantas sob alagamento apresentarem menor área foliar. Efeitos discretos do alagamento sobre o crescimento e desenvolvimento de plantas, como o observado e C. pachystachya já foram observados em alguns estudos com outras espécies que ocorrem em locais sujeitos ao alagamento, por exemplo, em Tabebuia avellanedae não foi observado redução na massa seca das folhas, somente de raiz e de caule (Davanso et al. 2002). No entanto, a maioria das espécies neotropicais tolerantes tem apresentado significativa redução do crescimento da planta como

Tabela 2. Parâmetros morfológicos e anatômicos de raízes pivotantes e secundárias (diageotrópicas) e de caules de plantas de Cecropia pachystachya Trec. cultivadas em solo drenado (D) e alagado por 30 dias (A). Médias seguidas de letras iguais nas linhas não diferem pelo teste de Tukey $(\leq 0,05, \mathrm{n}=10)$.

\begin{tabular}{lrr}
\hline Parâmetros & \multicolumn{2}{c}{ Tratamentos } \\
\cline { 2 - 3 } & \multicolumn{1}{c}{$\mathrm{D}$} & $\mathrm{A}$ \\
\hline Diâmetro da base do caule $(\mathrm{cm})$ & $1,28 \mathrm{a}$ & $1,13 \mathrm{a}$ \\
Lenticelas $\left(\mathrm{n}^{-0} \mathrm{~cm}^{-2}\right)$ & $1,80 \mathrm{~b}$ & $16,50 \mathrm{a}$ \\
Número de raízes adventícias & $0,00 \mathrm{~b}$ & $13,70 \mathrm{a}$ \\
Espessura do córtex da raiz pivotante $(\mu \mathrm{m})$ & $140,00 \mathrm{~b}$ & $230,60 \mathrm{a}$ \\
Número de camadas de células do córtex da raiz pivotante & $17,50 \mathrm{a}$ & $14,00 \mathrm{a}$ \\
Diâmetro das células do córtex da raiz pivotante $(\mu \mathrm{m})$ & $7,56 \mathrm{~b}$ & $16,85 \mathrm{a}$ \\
Espessura do córtex de raízes secundárias $(\mu \mathrm{m})$ & $137,12 \mathrm{~b}$ & $348,89 \mathrm{a}$ \\
Número de camadas de células do córtex das raízes secundárias & $17,00 \mathrm{a}$ & $20,33 \mathrm{a}$ \\
Diâmetro das células do córtex das raízes secundárias $(\mu \mathrm{m})$ & $7,92 \mathrm{~b}$ & $25,00 \mathrm{a}$ \\
Espessura do córtex do caule $(\mu \mathrm{m})$ & $151,27 \mathrm{a}$ & $139,19 \mathrm{a}$ \\
Número de camadas de células do córtex do caule & $19,00 \mathrm{a}$ & $11,30 \mathrm{a}$ \\
Diâmetro das células do córtex do caule $(\mu \mathrm{m})$ & $8,72 \mathrm{a}$ & $11,97 \mathrm{a}$ \\
Diâmetro dos elementos de vaso do caule $(\mu \mathrm{m})$ & $17,45 \mathrm{a}$ & $10,59 \mathrm{~b}$ \\
\hline
\end{tabular}


um todo, como foi observado por Kolb et al. (1998) em Sebastiania commersoniana, por Mielke et al. (2003) em Genipa americana.

Assim como neste estudo e nos outros mencionados no parágrafo anterior, o grande efeito do alagamento é sobre o desenvolvimento do sistema de raízes, que no caso de $C$. pachystachya com 30 dias de alagamento se observou morte de parte do sistema. Embora tenha sido observado em Sesbania virgata (Davanso-Fabro et al. 1998), em Cytharexyllum myrianthum (Andrade et al. 1999) e em Anona glabra (Mielke et al. 2005), são raras as espécies tolerantes estudadas que não apresentaram redução do crescimento das raízes quando alagadas.

Para Wiedenroth (1993) e Armstrong et al. (1994), a diminuição do crescimento de alguns órgãos, durante o alagamento, pode ser uma estratégia para economizar energia e manter um funcionamento mínimo do metabolismo nas regiões mais afetadas pela hipoxia. Assim, a sobrevivência da planta é dependente de um balanço na distribuição de fotoassimilados entre as suas várias partes. A diminuição da TCR da raiz e do caule das plantas de C. pachystachya cultivadas em solo alagado pode ser uma conseqüência da menor quantidade de energia disponível, já que devido à hipoxia ocasionada pelo alagamento as plantas tendem a desviar o metabolismo para vias fermentativas, resultando em uma redução dos níveis energéticos (Crawford \& Braendle 1996).

Os resultados de área foliar e índice de esclerofilia indicam, também, que houve uma distribuição de fotoassimilados privilegiando o aumento da espessura das folhas em detrimento da expansão da área foliar nas plantas alagadas. Estas respostas podem ser importantes para que a planta economize água. Em alguns estudos, tem sido observado que durante o alagamento as plantas ficam sujeitas ao déficit hídrico, principalmente pela menor absorção de água causada por modificações na permeabilidade das membranas das células das raízes, em consequiência do ambiente hipóxico, o que leva a uma menor condutividade hidráulica nas raízes (Coutts 1981; Pimenta et al. 1994; Else et al. 2001).

Em C. pachystachya foi observado também redução da condutância estomática e da taxa fotossintética quando submetida ao alagamento. Possivelmente o aumento do índice de esclerofilia das folhas das plantas sob alagamento, provocando redução na perda de água, contribuiu para que não houvesse uma queda ainda maior da condutância estomática e da taxa fotossintética. Pois, apesar de ter ocorrido diminuição da fotoassimilação, as TCR de todas as partes da planta ainda foram positivas e não muito distantes das plantas não alagadas, indicando que são respostas que efetivamente auxiliam a tolerância de C. pachystachya ao alagamento, e ajudam a explicar a sua alta ocorrência em locais sujeitos à inundação.

O fechamento estomático pode ser um mecanismo de tolerância à inundação apresentado por C. pachystachya uma vez que além de reduzir a demanda de água reduzem também a absorção de nutrientes, e entre estes os potencialmente tóxicos como o ferro e o manganês, como sugerido por Jackson \& Drew (1984) estudando plantas herbáceas alagadas. Possivelmente variações nos níveis hormonais provocados pelo alagamento, principalmente aumento do ácido abscísico (ABA) e queda das citocininas, podem estar interferindo no movimento estomático
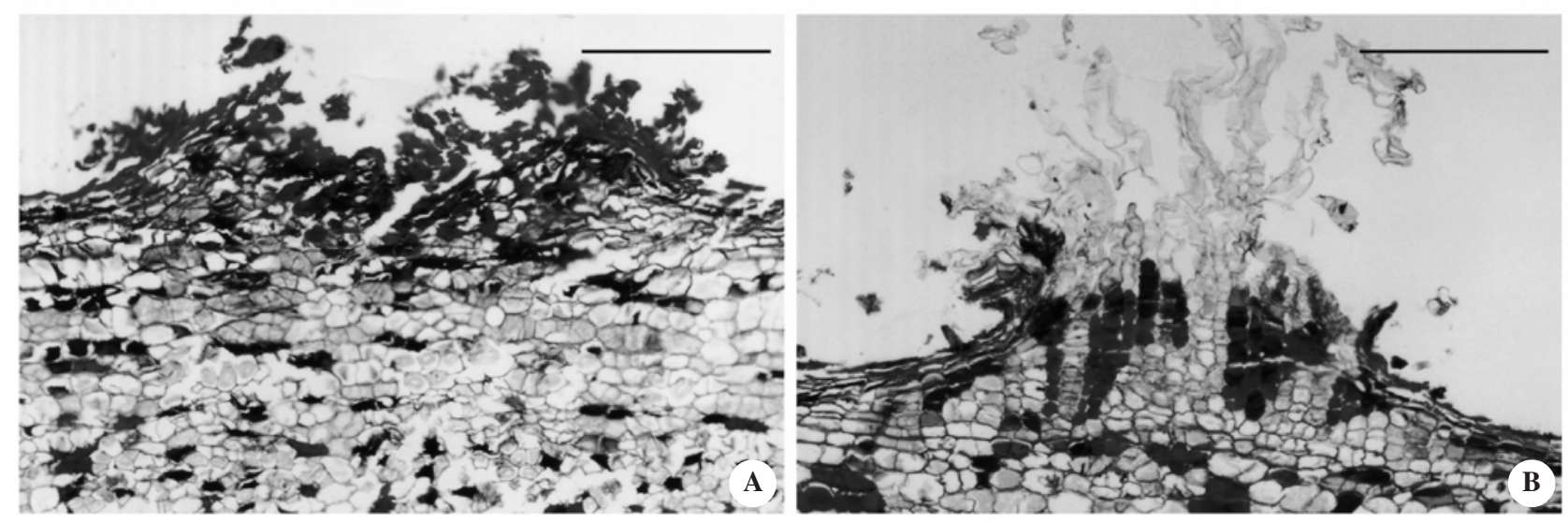

Figura 3. Micrografias ópticas de lenticelas da base do caule de plantas de Cecropia pachystachya Trec. cultivadas em solo drenado (A) e alagado por 30 dias (B). Barras $=30 \mu \mathrm{m}$. 
como já observado em outros estudos com plantas em condições de hipoxia (Selman \& Sandana 1972; Neuman \& Smit 1991; Zhang \& Zhang 1994).

Em $C$. pachystachya as porcentagens de reduções na condutância estomática nos diferentes períodos de alagamento ( $47 \%$ em dois, $53 \%$ em cinco e $70 \%$ em 15 dias) foram semelhantes àquelas apresentadas pela taxa fotossintética $(47 \%$ em dois, $46 \%$ em cinco e $75 \%$ em 15 dias). Estes resultados indicam que o fechamento estomático deve ser a grande, se não a única, causa de redução da taxa fotossintética nesta espécie, ou seja, possivelmente nesta espécie o alagamento não deve afetar a atividade da Rubisco ou provocar disfunções nos cloroplastos como sugerido por Liao \& Lin (1994; 1996) e Dreyer (1994). O fato de não ocorrer um efeito do alagamento diretamente no processo fotossintético, e sim indiretamente através do fechamento estomático, é um importante indício da capacidade de recuperação nos níveis de taxa fotossintética após o período de alagamento.

Dentre as variáveis analisadas para o caule de C. pachystachya, o diâmetro dos elementos de vaso foi menor para as plantas sob alagamento. $\mathrm{O}$ menor diâmetro destes vasos dificulta a embolia o que garante o fluxo de água, conforme sugerido por Zimmermann \& Milburn (1982). A manutenção do fluxo de água é importante tendo em vista que o alagamento pode reduzir a absorção de água pelas plantas (Coutts 1981). Kolb et al. (1998) verificaram que plantas alagadas de Sebastiania commersoniana apresentaram elementos de vasos mais estreitos que as plantas controle, em contraste ao observado em Sesbania virgata (Davanso-Fabro et al. 1998).

Diferentemente do que ocorreu em outras espécies quando alagadas, como Jacaranda puberula (Pimenta et al. 1996), Peltotophorum dubium (Medri et al. 1998) e Tabebuia avellanedae (Davanso et al. 2002), em C. pachystachya não foi observado aumento no diâmetro da base do caule. Este resultado está de acordo com a não variação de outros parâmetros avaliados na base do caule, como a espessura, número de camadas de células e diâmetro das células do córtex.

O aumento de diâmetro da base do caule encontrado em várias espécies quando submetidas ao alagamento pode estar relacionado ao crescimento radial de células do córtex (Kawase 1981), que leva ao desenvolvimento de grandes espaços de ar (aerênquima) importantes na difusão de oxigênio da parte aérea para as raízes. Estes efeitos podem ser desencadeados pelo etileno, que possui seus níveis aumentados sob condições de hipoxia, como sugerido por Pimenta et al. (1996) e por Medri et al. (1998).

A observação de que C. pachystachya não apresenta aumento no diâmetro da base do caule, possibilita levantar duas hipóteses: primeira, que esta espécie tolera anaerobiose não necessitando de oxigênio vindo da parte aérea e segunda, que a espécie já é bem suprida de espaços aéreos nesta região mesmo sem estar em condições de alagamento.

Considerando as variações anatômicas ocorridas nas raízes, a segunda hipótese parece mais plausível, pois tanto a raiz pivotante como as raízes secundárias diageotrópicas das plantas alagadas apresentaram maior diâmetro das células levando a uma maior espessura do córtex, pois este tecido não apresentou maior número de camadas de células. Estes resultados indicam aumento dos espaços intercelulares em função do novo rearranjo das células das raízes das plantas sob alagamento, que são maiores. Aumento dos espaços intercelulares também foi observado em vários outros estudos com plantas alagadas (Kawase 1981; Youssef \& Saenger 1996; Medri et al. 2002). Além disso, indicam também a necessidade de ampliação de espaços aéreos no interior das raízes em conexão direta com a base do caule, para facilitar tanto a difusão descendente de oxigênio quanto a ascendente de produtos potencialmente tóxicos como etanol, acetaldeído e etileno, que tem seus níveis aumentados pelo alagamento (Tsukahara \& Kozlowski 1985; Joly 1991).

Somando-se às modificações morfo-anatômicas ocorridas no córtex das raízes das plantas alagadas ocorreram também em $C$. pachystachya um aumento de lenticelas, que se apresentaram mais proeminentes e com poucas células suberizadas no tecido de enchimento e o aparecimento de raízes adventícias. Tais estruturas provavelmente favorecem a sobrevivência das plantas durante períodos de baixa disponibilidade de oxigênio no solo, contribuindo também com a difusão do mesmo da atmosfera para os tecidos internos, e liberação dos compostos potencialmente tóxicos. Tem sido detectado aumento na formação de lenticelas em muitas espécies quando alagadas, como P. dubium (Medri et al. 1998), T. avellanedae (Davanso et al. 2002).

Há muitas evidências de que a formação de novas raízes induzidas pelo alagamento representa importante contribuição para a sobrevivência das plantas submetidas a este estresse, como foi sugerido para T. avellanedae (Davanso et al. 2002). Raízes formadas durante as condições de hipoxia são mais 
ramificadas, superficiais e possuem mais aerênquima do que raízes laterais primárias, e assim, são mais eficientes no transporte de água, oxigênio e íons (Visser et al. 1997).

Provavelmente a somatória de todas estas respostas morfo-anatômicas ocorridas após 30 dias de alagamento, possibilita que as plantas de C. pachystachya, mesmo sob condições hipóxicas, mantenham um considerável nível de respiração aeróbia nas raízes, e consequentemente de produção energética. Todas estas observações e sugestões corroboram as discretas reduções de crescimento que ocorreram nesta espécie quando submetidas ao alagamento.

As respostas apresentadas pelas plantas alagadas de $C$. pachystachya indicam que a espécie pode tolerar períodos curtos de alagamento, mantendo uma satisfatória produção energética possivelmente através da aceleração da glicólise, como sugerido por McManmon \& Crawford (1971) e Vartapetian et al. (2003). Para períodos mais prolongados de alagamento a produção energética pode ser garantida por respiração aeróbia em razão das modificações morfoanatômicas. Entretanto, a energia produzida durante o período de alagamento deve ser inferior àquela produzida durante períodos de normoxia. Porém, este menor nível energético produzido é suficientemente superior aquele apresentado por outras espécies que, diferentemente de $C$. pachystachya, não obtém sucesso em áreas sujeitas ao alagamento.

\section{Agradecimentos}

Este trabalho foi parcialmente financiado pela CAPES-PROAP - Coordenação de Aperfeiçoamento de Pessoal de Nível Superior - Programa de Apoio à Pós-Graduação.

\section{Referências bibliográficas}

Alaoui-Sossé, B.; Gérard, B.; Toussaint, M. \& Badot, P. 2005. Influence of flooding on growth, nitrogen availability in soil, and nitrate reduction of young oak seedlings (Quercus robur L.). Annals of Forest Science 62: 593-600.

Andrade, A.C.S.; Ramos, F.N.; Souza, A.F.; Loureiro, M.B. \& Bastos, R. 1999. Flooding effects of Cytharexyllum myrianthum Cham. And Genipa americana L.: responses of two neotropical lowland species. Revista Brasileira de Botânica 22: 281-285.

Armstrong, W.; Braendle, R. \& Jackson, M.B. 1994. Mechanisms of flood tolerance in plants. Acta Botanica Neerlandica 43: 307-358.
Coutts, M.P. 1981. Effect of waterlogging on dormant sitka spruce seedlings. Annals of Botany 47: 747-753.

Crawford, R.M.M. \& Braendle, R. 1996. Oxygen deprivation stress in a changing environment. Journal Experimental of Botany 47: 145-159.

Davanso-Fabro, V.M.; Medri, M.E.; Bianchini, E. \& Pimenta, J.A. 1998. Tolerância à inundação: aspectos da anatomia ecológica e do desenvolvimento da Sesbania virgata (CAV.) Pers. (Fabaceae). Brazilian Archives of Biology and Technology 41: 475-482.

Davanso, V.M.; Souza, L.A.; Medri, M.E.; Pimenta, J.A. \& Bianchini, E. 2002. Photosynthesis, growth and development of Tabebuia avellanedae Lor. Ex Griseb. (Bignoniaceae) in flooded soil. Brazilian Archives of Biology and Technology 45: 375-384.

Drew, M.C. 1991. Oxygen deficiency in the root environment and plant mineral nutrition. Pp. 303-316. In: M.B. Jackson \& D.D. Lambers (eds.). Plant life under deprivation. Netherlands, SPB Academic Publishing, The Hague.

Dreyer, E. 1994. Compared sensitivity of seedlings from 3 woody especies (Quercus rubor L., Quercus rubra L. and Fagus silvatica L.) to water-logging and associated root hypoxia: effects on eater relations and photosynthesis. Annales des Sciences Forestières 51: 417-429.

Else, M.A.; Coupland, D.; Dutton, L. \& Jackson M.B. 2001. Decreased root hydraulic conductivity reduces leaf water potential, initiates stomatal closure and slows leaf expansion in flooded plants of castor oil (Ricinus communis) despite diminished delivery of ABA from the roots to shoots in xylem sap. Physiologia Plantarum 111: $46-54$.

Evans, D.E. 2004. Aerenchyma formation. New Phytologist 161: $35-49$

Fernandez, M.D. 2006. Changes in photosynthesis and fluorescence in response to flooding in emerged and submerged leaves of Pouteria orinocoensis. Photosynthetica 44: 32-38.

Jackson, M.B. \& Drew, M.C. 1984. Effect of flooding on growth and metabolism of herbaceous plants. Pp. 47-128. In: T.T. Kozlowski (ed.). Flooding and plant growth. London, Academic.

Johansen, D.A. 1940. Plant microtechnique. New York, McGraw-Hill.

Joly, C.A. 1991. Flooding tolerance in tropical trees. Pp. 23-34. In: M.B. Jackson; D.D. Daves \& H. Lambers (eds.). Plant life under oxygen stress. Netherlands, SPB Academic Publishing, The Hague.

Joly, C.A. 1994. Flooding tolerance: a re-interpretation of Crawford's metabolic theory. Proceedings of the Royal Society of Edinburgh 102B: 343-354.

Karnovsky, M.J. 1965. A formaldehyde-glutaraldehyde fixative of high osmolality for use in electron microscopy. Journal of Cell Biology 27: 137A-138A.

Kawase, M. 1981. Anatomical and morphological adaptation of plants to waterlogging. HortScience 16: 30-34.

Kolb, R.M.; Medri, M.E.; Bianchini, E.; Pimenta, J.A.; Giloni, P.C. \& Correa, G.T. 1998. Anatomia ecológica de Sebastiania commersoniana (Baillon) Smith \& Downs (Euphorbiaceae) submetida ao alagamento. Revista Brasileira de Botânica 21: 305-312. 
Laan, P.; Clement, J.M.A.M.; Blom, C.W.M. 1991. Growth and development of Rumex roots as affected by hypoxic and anoxic conditions. Plant and Soil 136: 145-151.

Liao, C.T. \& Lin, C.H. 1994. Effect of flooding stress on photosynthetic activities of Momordica charantia. Plant Physiology and Biochemistry 32: 479-485.

Liao, C.T. \& Lin, C.H. 1996. Photosynthetic responses of grafted bitter melon seedlings to flood stress. Environmental and Experimental Botany 36: 167-172.

Lorenzi, H. 1992. Árvores Brasileiras: manual de identificação e cultivo de plantas arbóreas nativas do Brasil. Nova Odessa, Ed. Plantarum.

Luque, R.; Souza, H.C. \& Kraus, J.E. 1996. Métodos de coloração de Roeser (1972) - modificado - e Kropp (1972) visando a substituição do azul de astra por azul de alcião 8GS ou 8GX. Acta Botanica Brasilica 10: 199-212.

Mano, Y.; Omori, F.; Takamizo, T.; Kindiger, B.; McK. Bird, R. \& Loaisiga, C.H. 2006. Variation for root aerenchyma formation in flooded and non-flooded maize and teosinte seedlings. Plant and Soil 281: 269-279.

Mantovani, W.; Rossi, L.; Neto, S.R.; Assad-Ludewigs, I.Y.; Wanderley, M.G.L.; Mello, M.M.R.F. \& Toledo, C.B. 1989. Pp. 235-267. Estudo fitossociológico de áreas de mata ciliar em Mogi-Guaçu, SP, Brasil. In: L.M. Barbosa (ed.) Simpósio sobre mata ciliar. Campinas, Fundação Cargill.

Matsui, T. \& Tsuchiya, T. 2006. Root aerobic respiration and growth characteristics of three Typha species in response to hypoxia. Ecological Research 21: 470-475.

McManmon, M. \& Crawford, R.M.M. 1971. A metafolic theory flooding tolerance: the significance of enzyme distribution and behavior. New Phytology 70: 299-306.

Medri, M.E.; Bianchini, E.; Pimenta, J.A.; Delgado, M.T. \& Correa, G.T. 1998. Aspectos morfo-anatômicos e fisiológicos de Peltophorum dubium (Spr.) Taub. Submetida ao alagamento e aplicação de ethrel. Revista Brasileira de Botânica 21: 261-267.

Medri, M.E.; Bianchini, E.; Pimenta, J.A.; Colli, S. \& Muller, C. 2002. Estudos sobre a tolerância ao alagamento em espécies arbóreas nativas da bacia do rio Tibagi. Pp. 133-172. In: M.E. Medri; E. Bianchini; O.A. Shibatta \& J.A. Pimenta (eds.). A Bacia do Rio Tibagi. Londrina, edição dos Editores.

Mielke, M.S.; Almeida, A.F.; Gomes, F.B.; Aguilar, M.A.G. \& Mangabeira, P.A.O. 2003. Leaf gás exchange, chlorophyll fluorecence and growth responses of Genipa americana seedlings to soil flooding. Environmental and Experimental Botany 50: 221-231.

Mielke, M.S.; Matos, E.M.; Couto, V.B.; Almeida, A.F.; Gomes, F.B. \& Mangabeira, P.A.O. 2005. Some photosynthetic and growth responses of Annona glabra L. seedlings to sol flooding. Acta Botanica Brasilica 19: 905-911.

Neuman, D.S. \& Smit, B.A. 1991. The influence of leaf water status and ABA on leaf growth and stomata of Phaseolus seedlings with hypoxic roots. Journal Experimental of Botany 42: 1499-1506.

Olivella, C.; Biel, C.; Vendrell, M. \& Save, R. 2000. Hormonal and physiological responses of Gerbera jamesonii to flooding stress. HortScience 35: 222-225.
Pimenta, J.A.; Orsi, M.M. \& Medri, M.E. 1994. Aspectos morfológicos e fisiológicos de Coleus blumei Benth. Submetido à inundação e à aplicação de ethrel e cobalto. Revista Brasileira de Biologia 53: 427-433.

Pimenta, J.A.; Bianchini, E.; Medri, M.E.; Muller, C.; Okamoto, J.M.; Francisconi, L.M.J. \& Correa, G.T. 1996. Aspectos da morfo-anatomia e fisiologia de Jacaranda puberula Cham. (Bignoniaceae) em condições de hipoxia. Revista Brasileira de Botânica 19: 215-220.

Pimenta, J.A.; Bianchini, E. \& Medri, M.E. 1998. Adaptations to flooding by tropical trees: morphological and anatomical modifications. Pp. 157-176. In: F.R. Scarano \& A.C. Franco (eds.). Ecophysiological strategies of xerophytic and amphibious plants in the neotropics. Rio de Janeiro, Oecologia Brasieliensis v. IV, PPGE-UFRJ.

Pryor, R.J.; Davison, N.J. \& Close, D.C. 2006. Waterlogging duration; Interspecific comparison of Leptospermum scoparium (Forst et Forst.f.), Acacia melanoxylon (R. Br.), Nothofagus cunninghamii (Hook.) and Eucalyptus abliqua (L'Herit). Austral Ecology 31: 408-416.

Rodrigues, R.R. 1989. Análise estrutural das formações florestais ripárias. Pp. 99-119. In: L.M. Barbosa (ed.). Simpósio sobre mata ciliar. Campinas, Fundação Cargill.

Rooge, G.D.; Pimenta, J.A.; Bianchini, E.; Medri, M.E.; Colli, S. \& Alves, L.M.T. 1998. Metabolismo respiratório de raízes de espécies arbóreas tropicais submetidas à inundação. Revista Brasileira de Botânica 21: 153-158.

Selman, I.W. \& Sandana, S. 1972. Growth responses of tomato plants in non-aerated water culture to foliar sprays of gibberellic acid and benzyladenine. Annals of Botany 36: 837-848.

Tsukahara, H. \& Kozlowski, T.T. 1985. Importance of adventitious roots to growth of flooded Platanus occidentalis seedlings. Plant and Soil 88: 123-132.

Vartapetian, B.B.; Andreeva, I.N.; Generozova, I.P.; Poliakova, L.; Maslova, I.P.; Dolgikh, Y.I. \& Stepanpva, A.Y. 2003. Functional electron microscopy in studies of plant response and adaptation to anaerobic stress. Annals of Botany 1: 155-172.

Visser, E.J.W.; Nabben, R.H.M.; Blom, C.W.P.M. \& Voesenek, L.A.C.J. 1997. Elongation by primary lateral roots and adventitious roots during conditions of hypoxia and high ethylene concentration. Plant, Cell and Environmental 20: 647-53.

Youssef, T. \& Saenger, P. 1996. Anatomical adaptative strategies to flooding and rhizosphere oxidation in mangrove seedlings. Australian Journal of Botany 44: 297-313.

Wiendenroth, E.M. 1993. Responses of roots to hypoxia: their structural and energy relations with the whole plant. Environmental and Experimental Botany 33: 41-51.

Zhang, J. \& Zhang, X. 1994. Can early wilting of old leaves account for much of the ABA accumulation in flooded pea plants? Journal of Experimental Botany 45: $1335-1342$.

Zimmermann, U. \& Milburn, J.A. 1982. Transport and storage of water. Pp. 135-152. In: O.L. Lange; P.S. Nobel; C.B. Osmond \& H. Ziegler (eds.). Phisiological plant ecology II. Water relations and carbon assimilation. v. 12B. New York, Springer-Verlag. 